\title{
Molecular target therapy - towards curative regimen: a 20-year experience in the treatment of acute promyelocytic leukemia (APL) in the Shanghai Institute of Hematology Zhi-Xiang Shen
}

Address: Shanghai Institute of Hematology, Department of Hematology, Ruijin Hospital, Shanghai Jiaotong University of Medicine, Shanghai, PR China

Email: Zhi-Xiang Shen - drshenzx@yahoo.com

from Current trends in leukemia, lymphoma and myeloma

White Plains, NY, USA. 31 January 2009

Published: 26 June 2009

Journal of Hematology \& Oncology 2009, 2(Suppl I):AI doi:I0.II86/I756-8722-2-SI-AI

This abstract is available from: http://www.jhoonline.org/content/2/SI/AI

(c) 2009 Shen; licensee BioMed Central Ltd.

Since the first description of acute promyelocytic leukemia (APL) in 1957 as the most malignant form of acute leukemia, several developments have paved the way to make this disease the most curable leukemia in adults and change the paradigm of cancer treatment. Therapy of APL was pioneered by Bernard et al in 1973 demonstrating a striking sensitivity to daunorubicin, probably related to significantly lower P-glycoprotein expression observed in APL cells compared to other subtypes of acute myeloid leukemia (AML).

The incorporation of ATRA, a noncytotoxic differentiating agent that is regarded as the first differentiation therapy has changed dramatically the management, outcome, and prognosis of APL.

ATRA was first introduced to clinical use for the treatment of APL in 1986. Since then, randomized studies in many centers around the world document a rising CR rate, a decrease in severe adverse effects, and a prolongation of remission duration. ATRA combined with anthracyclinebased chemotherapy can achieve CR in $90-95 \%$ of patients with APL and cure the disease in $70-75 \%$ of the cases. Combination therapy with ATRA and chemotherapeutic agents should now be considered as a standard treatment of APL.

Over the last decade, tremendous efforts have been made to elucidate the molecular genesis of APL, as well as the mechanism of action of ATRA. The mechanism of action of ATRA can be summarized as follows: 1. The binding of ATRA to RAR receptors causes degradation of PML-RAR $\alpha$ protein through the ubiquitin-proteosome and caspase system, leading to restoration of terminal differentiation of promyelocytes; 2. Exposure of APL cells to ATRA in vitro or in vivo induces relocalization of PML and restores the normal structure of PODs; and 3. Under the action of ATRA, CoR is dissociated from the repressive complex, whereas CoA (coactivator) is recruited to the complex. As a result, the repression of transcriptional activation of target genes is relieved and the differentiation of promyelocytes is restored.

Treatment of APL by arsenic compounds represents a successful example of apoptosis induction therapy of acute leukemia. $\mathrm{As}_{2} \mathrm{O}_{3}$ exerts dual effects on APL cells. Studies in vitro with NB4 cells showed that a higher concentration of $\mathrm{As}_{2} \mathrm{O}_{3}(0.5-1.0 \mu \mathrm{M})$ induced apoptosis with typical morphological changes, DNA laddering on agarose gel electrophoresis, appearance of an apoptotic peak on flow cytometric analysis, and increased expression of annexin $\mathrm{V}$ on the cell surface membrane. At lower concentrations, $\mathrm{As}_{2} \mathrm{O}_{3}$ can induce APL cells to partially differentiate along the granulocytic pathway.

Synergistic effect of ATRA and $\mathrm{As}_{2} \mathrm{O}_{3}$ was confirmed by several research works in vivo and in vitro. The first clinical trial was completed by SIH in 2001. CR rate was same 
as ATRA or $\mathrm{As}_{2} \mathrm{O}_{3}$ alone, but the median day to CR was very short, only 26 days, and OS and DFS were much better than ATRA or $\mathrm{As}_{2} \mathrm{O}_{3}$ alone. Now timing and dose of $\mathrm{As}_{2} \mathrm{O}_{3}$ combined with ATRA in newly diagnosed APL patients need to be confirmed.

Recently, several genetic and phenotypic characteristics of acute promyelocytic leukemia (APL) blasts have been demonstrated. These include the PML/RAR $\alpha$ fusion and the transcription co-repressor complex recruited at the promoter of target genes by the hybrid protein, the intense and homogeneous expression of the CD33 antigen, and absence of multidrug resistance-related phenotype, a frequently mutated and constitutively activated FLT3 receptor. Such genotypic and phenotypic features are targeted by agents currently in use in front-line therapy or at relapse (i.e., retinoids, $\mathrm{As}_{2} \mathrm{O}_{3}$, anthracyclines and antiCD33 monoclonal antibodies), and by novel agents that many find a place in future treatments such as histone deacetylase and FLT3 inhibitors.
Publish with Biomed Central and every scientist can read your work free of charge

"BioMed Central will be the most significant development for disseminating the results of biomedical research in our lifetime. " Sir Paul Nurse, Cancer Research UK

Your research papers will be:

- available free of charge to the entire biomedical community

- peer reviewed and published immediately upon acceptance

- cited in PubMed and archived on PubMed Central

- yours - you keep the copyright

Submit your manuscript here:

http://www.biomedcentral.com/info/publishing_adv.asp 